\title{
National health insurance scheme: how protected are households in Oyo State, Nigeria from catastrophic health expenditure?
}

\author{
Olayinka Stephen Ilesanmi1 ${ }^{1,}$, Akindele Olupelumi Adebiyi1 ${ }^{1,2}$, Akinola Ayoola Fatiregun ${ }^{3}$
}

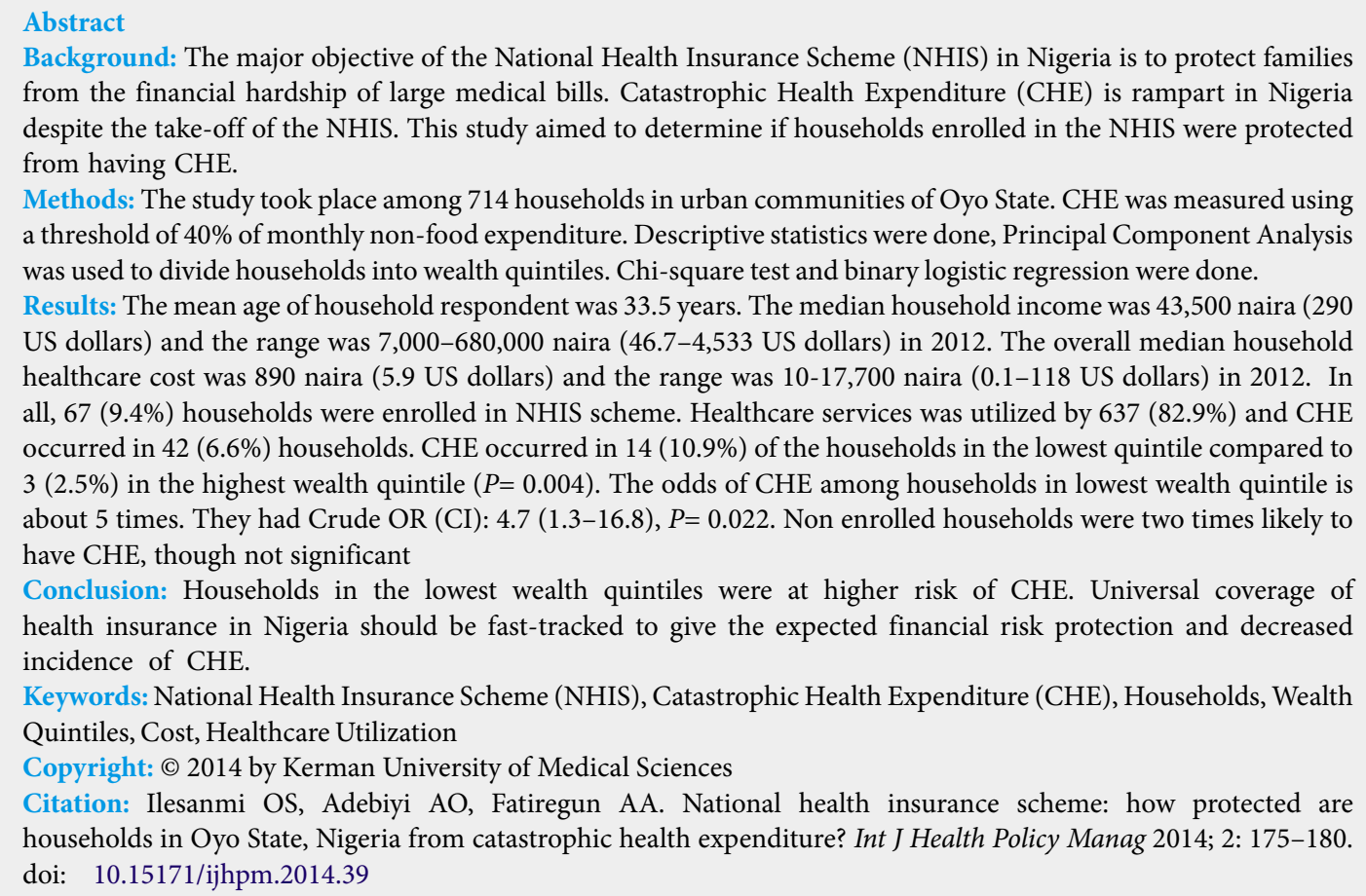

Background: The major objective of the National Health Insurance Scheme (NHIS) in Nigeria is to protect families from the financial hardship of large medical bills. Catastrophic Health Expenditure (CHE) is rampart in Nigeria despite the take-off of the NHIS. This study aimed to determine if households enrolled in the NHIS were protected from having CHE.

Methods: The study took place among 714 households in urban communities of Oyo State. CHE was measured using a threshold of $40 \%$ of monthly non-food expenditure. Descriptive statistics were done, Principal Component Analysis was used to divide households into wealth quintiles. Chi-square test and binary logistic regression were done.

Results: The mean age of household respondent was 33.5 years. The median household income was 43,500 naira (290 US dollars) and the range was 7,000-680,000 naira (46.7-4,533 US dollars) in 2012. The overall median household healthcare cost was 890 naira (5.9 US dollars) and the range was 10-17,700 naira (0.1-118 US dollars) in 2012. In all, 67 (9.4\%) households were enrolled in NHIS scheme. Healthcare services was utilized by $637(82.9 \%)$ and CHE occurred in $42(6.6 \%)$ households. CHE occurred in $14(10.9 \%)$ of the households in the lowest quintile compared to $3(2.5 \%)$ in the highest wealth quintile $(P=0.004)$. The odds of CHE among households in lowest wealth quintile is about 5 times. They had Crude OR (CI): 4.7 (1.3-16.8), $P=0.022$. Non enrolled households were two times likely to have CHE, though not significant

Conclusion: Households in the lowest wealth quintiles were at higher risk of CHE. Universal coverage of health insurance in Nigeria should be fast-tracked to give the expected financial risk protection and decreased incidence of CHE.

Keywords: National Health Insurance Scheme (NHIS), Catastrophic Health Expenditure (CHE), Households, Wealth Quintiles, Cost, Healthcare Utilization

Copyright: @ 2014 by Kerman University of Medical Sciences

Citation: Ilesanmi OS, Adebiyi AO, Fatiregun AA. National health insurance scheme: how protected are households in Oyo State, Nigeria from catastrophic health expenditure? Int J Health Policy Manag 2014; 2: 175-180. doi: $10.15171 /$ ijhpm.2014.39

Article History:

Received: 2 February 2014 Accepted: 24 April 2014 ePublished: 28 April 2014

${ }^{\star}$ Correspondence to: Olayinka Stephen Ilesanmi Email: ileolasteve@yahoo.co.uk

\section{Introduction}

Families who spend $40 \%$ or more of their non-food expenditure on healthcare are likely to be impoverished $(1,2)$. However, high healthcare costs does not necessarily equate to Catastrophic Health Expenditure (CHE) as this refers to any healthcare expenditure that threatens a household's financial capacity to maintain its subsistence needs $(3,4)$. Health insurance has a very important role in healthcare and financial protection, especially for the poor. It helps insured people access expensive healthcare services and prevents CHE (5).

The National Health Insurance Scheme (NHIS) was introduced in 2006 in Nigeria with the aim of improving access to healthcare and reducing the financial burden of out-ofpocket payments for healthcare services $(6,7)$. The expectation is that paying for healthcare should not be a burden to households enrolled in the NHIS. Enrolled households are expected to have financial protection. Paradoxically financial hardship is still common in Nigeria and this has led many households into CHE despite the existence of NHIS.

Despite the existence of NHIS the most prevalent form of healthcare financing in Nigeria remains out-of-pocket expenditure (8). Low coverage of the population by NHIS is responsible. It is still about $5 \%$ among the general population (9). The scheme was established to reduce the negative effects of user fees and also help toward reducing the high healthcare expenses. However, it could only cover the formal sector of the economy against its initial intention. The formal sector includes the federal, state, and other taxable establishments. But the scheme currently covers mainly the federal government employees, although some organised private sector like banks also have their private health insurance arrangements. To ensure effectiveness, principal-agent relationship was established among the actors-NHIS Health Maintenance Organisations (HMOs), employers and providers. While the NHIS and beneficiaries are the principals, HMOs and providers serve as the agents in the scheme arrangement $(7,10)$. About $95 \%$ of the population who are in need of financial risk protection against ill health are yet to be covered by the scheme (11). The scheme has potentials to give every employee of the federal government, his/her spouse and four children below the age of 18 years access to healthcare. Those under the scheme are required to register with their choice providers. The beneficiaries of the scheme are expected to pay $15 \%$ of their monthly salary to the scheme. But the federal 
government pays $10 \%$ while the remaining $5 \%$ is expected to be paid by the beneficiaries. Enrolee just have to pay at most of $10 \%$ of the cost of care received (7).

Since the introduction of the NHIS in Nigeria studies assessing the willingness of the people to join the scheme have been conducted. Levels of satisfaction with the scheme and equity of care received from healthcare providers among enrolee and non-enrolee have also been studied (12-14). To the best of our knowledge, no assessment of the NHIS's financial protection effect has been done by comparing enrolee and non-enrolee of the scheme in Nigeria. There is also limited evidence about the financial protection from catastrophic health spending in Nigeria among households enrolled in NHIS. This study therefore, aimed at determining if NHIS protects households in Oyo State, South western Nigeria from having CHE.

\section{Methods}

This explorative cross-sectional study took place in urban communities of Oyo State, South-West Nigeria. Oyo State is one of the 36 states in Nigeria with a population of approximately 5,580,894 and a land mass of 27,249 square kilometres (15). It is bounded by Kwara State in the North, Ogun State in the South, Osun State in the East and the Republic of Benin in the West. The studied communities were in Ibadan South west Local Government Areas of Oyo state. There are several federal government establishments in the state. However, most of the federal establishments are located at the urban centres. The residents are mainly of Yoruba ethnicity; they have similar cultural values and speak predominantly Yoruba Language.

A multistage sampling technique was used to select the households:

Stage 1: Using the sampling frame of urban LGAs in Oyo State, an urban LGA (Ibadan South West) was selected by balloting. Stage 2: From the list of the 12 wards in Ibadan South West LGA five were selected using tables of random numbers.

Stage 3: A list of all the streets was obtained from the Local Government Area secretariat. A rapid mapping of a random sample of selected street gave an average of 90 eligible households per street. The number of street required from each selected ward were 1,2, or 3 depending on the population. Stage 4: All consenting households that met the inclusion criteria in the selected streets were included in the study.

A pre-tested interviewer administered questionnaire was used to collect information on socio-demographic variables, utilization of healthcare services, and cost of healthcare services utilized.

Households who have resided in the selected streets for at least one year were included in the study. Where the heads were not available, the spouse or other nominated household representative aged 18 years and above were interviewed. Information was obtained from 714 household heads/ representatives. Visitors and non-residents of the selected streets were excluded. A household refers to a group of two or more persons living together in the same house and sharing common food or other arrangements for essential living (5, 16). Household Healthcare Expenditure is defined as the outof-pocket expenditures on consultation, investigations, drugs, hospital bed, transportation to and from the hospital or where treatment was received and other cost directly related to the restoration, improvement, and maintenance of health (17). Expenditure of each household member on all other item and food was collected and computed at household level. Questions on utilization of outpatients and inpatients health services and cost of care were asked retrospectively to cover 12 months and one month respectively (18). In computing health expenditure cost of care was used directly for those who utilized only out patient care. One twelfth (1/12) of the cost of care was computed for those who utilized inpatient care only. However, individual who received inpatient care 12 months before the study and outpatient care one month before the study had the cost of outpatient care added to one twelfth of inpatient cost of care. Cost was also computed for all the members in the household. This gives the monthly health expenditure at the household level (18). Data was collected in year 2012, a dollar was one hundred and fifty naira (1 US dollar $=150$ naira)

CHE was measured using a threshold of $40 \%$ of monthly non-food expenditure (19). Computation of all household expenditure was done, food expenditure was subtracted from this to have the household non-food expenditure. Household consumption expenditure is the value of consumer goods and services acquired, used or paid for by a household for the satisfaction of the needs and wants of its members.

Data was entered and analysed using SPSS 21 (SPSS Inc., Chicago, IL, USA). Principal Component Analysis (PCA) in Stata (Stata Corporation, College Station, Texas) was used to categorise households into wealth quintiles from the list of household assets owned. The input into the PCA was information on ownership of house and other key assets such as stove, electric fan, refrigerator, air conditioner, radio, television, generator, piped water in the household, bicycle, motor vehicle, upholstered chairs, sewing machine, and washing machine $(20,21)$. For calculation of distribution cut points, quintiles was used. Each member was assigned the wealth index score of his or her household. The quintiles were Q1= Lowest, Q2= Second, Q3= Middle, Q4= Fourth, Q5= Highest Household.

Descriptive statistics were done. Total cost of care was summarized using median and range due to its non-parametric nature while age was summarized with mean and standard deviation. Proportions were presented in tables. Comparison of household characteristics was done by location. Characteristics of households without NHIS coverage was also compared. In the urban area enrolee were also compared with non-enrolee of NHIS with respect to socio-demographic characteristics. Association between socio-demographic characteristics and occurrence of $\mathrm{CHE}$ were explored with the Chi Square test. Binary logistic regression were used to identify both crude and adjusted factors associated with $\mathrm{CHE}$. Associations were all explored at 5\% level of significance.

\section{Results}

The median household income was 43,500 naira (290 US dollars) and the range was 7,000-680,000 naira (46.7-4,533 US dollars). The overall median household healthcare cost was 890 naira (5.9 US dollars) and the range was $10-17,700$ naira (0.1-118 US dollars).

Table 1 shows the socio-demographic characteristics of the household respondents. More than a quarter 199 (27.9\%) were 
male. In all 149 (20.9\%) were forty years and above. Majority of the respondents 549 (76.9\%) were married. The mean age of household respondent was $33.5 \pm 8.6$ years. The range was 18-65 years.

The household characteristics of the respondents is as shown in Table 2. Only 134 (18.8\%) of the households had five members and above. The mean number of household members was $3.6 \pm 1$. Number of households in each of the wealth quintiles is as shown. Concerning enrolment in NHIS only 67 (9.5\%) households were enrolled. Healthcare services was utilized by $637(82.9 \%)$ households in the year before data collection. CHE is present in $42(6.6 \%)$.

Table 3 shows the comparison of household variables in those having and not having CHE among the 637 (82.9\%) households that utilized healthcare. Overall, CHE occurred in

Table 1. Socio-demographic characteristics of the households respondents

\begin{tabular}{lc}
\hline Characteristics & Number (\%) \\
\hline Gender & $199(27.9)$ \\
Male & $515(72.1)$ \\
Female & \\
Age & $278(38.9)$ \\
$<30$ years & $287(40.2)$ \\
$30-39$ years & $149(20.9)$ \\
$\geq 40$ years & \\
Marital status & $92(12.9)$ \\
Single & $549(76.9)$ \\
Married & $73(10.2)$ \\
\hline Others* & \\
\hline
\end{tabular}

*widowed, divorced, separated, co habiting

Table 2. Household characteristics of the respondents

\begin{tabular}{ll}
\hline Household characteristics & Number (\%) \\
\hline Number of individual in the household $(\mathbf{N}=\mathbf{7 1 4})$ & $580(81.2)$ \\
$<5$ & $134(18.8)$ \\
$\geq 5$ & \\
Wealth quintiles of household $(\mathbf{N}=\mathbf{7 1 4})$ & $142(19.9)$ \\
Lowest & $143(20.0)$ \\
Second & $143(20.0)$ \\
Middle & $143(20.0)$ \\
Fourth & $143(20.0)$ \\
Highest & \\
Household enrolment in NHIS $(\mathbf{N}=\mathbf{7 1 4})$ & $67(9.4)$ \\
Yes & $647(90.6)$ \\
No & \\
\hline Utilization of healthcare services $(\mathbf{N}=\mathbf{7 1 4})$ & $637(89.2)$ \\
Yes & $77(10.8)$ \\
No & $595(93.4)$ \\
\hline CHE ( $\mathbf{~}=637)$ & \\
Have CHE & \\
Do not have CHE & \\
\hline & \\
\hline
\end{tabular}

$14(10.9 \%)$ of the households in the lowest quintile compared to $3(2.5 \%)$ in the highest wealth quintile $(P=0.004)$.

The determinants of CHE are shown in Table 4. Households in lowest wealth quintile are about 5 times likely to have CHE. They had Crude OR (CI): 4.7 (1.3-16.8), $P=0.017$ and adjusted OR (CI): 4.7 (1.3-17.3), $P=0.022$. Households not enrolled in NHIS were two times likely to have CHE compared to enrolled households, this is not significant statistically.

\section{Discussion}

This study explored the protection NHIS offered against CHE to households in Oyo State, Nigeria. Limited evidence exist about the extent of protection from catastrophic health spending in Nigeria of NHIS enrolee and there is no in-depth assessment of the NHIS's financial protection effect. The protective effect of insurance against catastrophic expenditure is particularly less among the households with lower socioeconomic status, who are typically more vulnerable to CHE. A financial protective effect of health insurance, especially amongst the most-poor Socio-Economic Status (SES) was found in Ghana (10). Also, it was found that health insurance led to a fourfold decrease in incidence of $\mathrm{CHE}$ in Rwandan households (22).

Regarding the enrolment in the NHIS or other health insurance only $9.4 \%$ of households interviewed were enrolled. This is slightly higher than previous documentation that NHIS only covers federal government employees and the coverage level is less than $5 \%$ of the general population (9). Limiting this study to urban areas where the NHIS enrolees are more could be responsible. Only few households in South East Nigeria are also on the NHIS and only $51(1.0 \%)$ households had a resident who was a primary enrolee in a health insurance scheme (23). This study showed a prevalence of CHE of $6.6 \%$ in urban South Western Nigeria. A higher proportion of $14.8 \%$ was reported by Onoka et al. among household studied in South Eastern Nigeria (19). Onwujekwe et al. also found $\mathrm{CHE}$ at $40 \%$ non-food expenditure in urban South Eastern Nigeria to be $15 \%$ (23).

This study has shown that some measures of financial risk protection is available to the enrolees of NHIS in Nigeria. However, financial protection in the presence of poverty is not evident in this study. For insurance to reduce the probability that households have to forego other subsistent needs for healthcare it should be made available to the poor. The most poor have been shown to suffer more from $\mathrm{CHE}$ in this study. A positive financial protective effect of health insurance, especially amongst the most-poor SES was found in Ghana (10). Also, it was found that health insurance led to a fourfold decrease in incidence of CHE in Rwanda (22). However, health insurance did not help financial protection from the catastrophic spending on healthcare in Zambia (26).

The overall protective effect of Health insurance seen in some other countries and places like Enugu State of Nigeria where the state civil servants have been included may not be evident in Oyo State if the breadth of the scheme is not extended. It is not enough to protect only those that are in the formal sector. NHIS guidelines stated that apart from those in the formal sector, efforts will be made to protect those that are also in the informal sector of the economy. It means artisans, traders, businessmen and women, and the poor will all participate in 
Table 3. Comparison of household variables and $\mathrm{CHE}$

\begin{tabular}{|c|c|c|c|c|}
\hline Variables & $\begin{array}{l}\text { Have CHE } \\
\text { N (\%) }\end{array}$ & $\begin{array}{c}\text { Do not have CHE } \\
\mathrm{N}(\%)\end{array}$ & Chi Square & $P$-value \\
\hline \multicolumn{5}{|c|}{ Number of Individual in the household } \\
\hline$<5$ & $31(6.0)$ & 485 (94.0) & 1.5 & 0.219 \\
\hline$\geq 5$ & $11(9.1)$ & $110(90.0)$ & & \\
\hline \multicolumn{5}{|c|}{ Wealth quintiles of household } \\
\hline Lowest & $14(10.9)$ & $115(89.1)$ & Linear by linear & \multirow{5}{*}{0.004} \\
\hline Second & $10(7.5)$ & $124(92.5)$ & Association & \\
\hline Middle & $10(7.9)$ & $117(92.1)$ & 8.3 & \\
\hline Fourth & $5(3.9)$ & $123(96.1)$ & & \\
\hline Highest & $3(2.5)$ & $116(97.5)$ & & \\
\hline \multicolumn{5}{|c|}{ Enrollment of household in NHIS } \\
\hline Yes & $1(1.7)$ & $57(98.3)$ & \multirow[t]{2}{*}{ Fisher's exact } & \multirow[t]{2}{*}{0.163} \\
\hline No & $41(7.1)$ & 538 (92.9) & & \\
\hline
\end{tabular}

Table 4. Factors associated with $\mathrm{CHE}$

\begin{tabular}{|c|c|c|c|c|c|c|c|c|}
\hline \multirow{3}{*}{ Household Variables } & \multicolumn{4}{|c|}{ Crude } & \multicolumn{4}{|c|}{ Adjusted } \\
\hline & \multirow[t]{2}{*}{$P$-value } & \multirow[t]{2}{*}{$\begin{array}{l}\text { Crude Odds } \\
\text { Ratio }\end{array}$} & \multicolumn{2}{|c|}{$\begin{array}{l}95 \% \text { Confidence } \\
\text { Interval for odds ratio }\end{array}$} & \multirow[t]{2}{*}{$P$-value } & \multirow[t]{2}{*}{$\begin{array}{l}\text { Adjusted } \\
\text { Odds Ratio }\end{array}$} & \multicolumn{2}{|c|}{$\begin{array}{l}95 \% \text { Confidence } \\
\text { Interval for odds ratio }\end{array}$} \\
\hline & & & Lower & Upper & & & Lower & Upper \\
\hline \multicolumn{9}{|c|}{ Number of Individual in the household } \\
\hline$<5$ & 0.221 & 0.6 & 0.3 & 1.3 & 0.104 & 1.9 & 0.9 & 3.9 \\
\hline \multicolumn{9}{|l|}{ Wealth quintiles } \\
\hline Lowest & 0.017 & 4.7 & 1.3 & 16.8 & 0.022 & 4.7 & 1.3 & 17.3 \\
\hline Second & 0.090 & 3.1 & 0.8 & 11.6 & 0.116 & 2.9 & 0.8 & 11.3 \\
\hline Middle & 0.075 & 3.3 & 0.9 & 12.3 & 0.091 & 3.2 & 0.8 & 12.4 \\
\hline Fourth & 0.542 & 1.6 & 0.4 & 6.7 & 0.580 & 1.5 & 0.4 & 6.7 \\
\hline \multicolumn{9}{|l|}{ Enrolment in NHIS } \\
\hline Enrolled & & 1.0 & & & & 1.0 & & \\
\hline Not enrolled & 0.150 & 4.3 & 0.6 & 32.2 & 0.424 & 2.3 & 0.3 & 18.2 \\
\hline
\end{tabular}

the financial risk protection (11).

Disparities in the quality of care provided for NHIS enrolee have been questioned by some authors (12). For the NHIS to achieve its objectives efforts should be made to reduce inequality. Counterpart payment of $10 \%$ cost of care by NHIS enrolee could have also been exaggerated by some healthcare providers.

\section{Conclusion}

Households in the lowest wealth quintiles were at higher risk of CHE. The protective effect of NHIS against CHE is not evident in this study. Limiting the NHIS to the formal sector who are urban dwellers is partly responsible. Universal coverage of health insurance in Nigeria should be fast-tracked to ensure financial risk protection and decreased incidence of CHE. Benefit incidence of the NHIS to the employees of the federal establishments in Oyo State, Southwest Nigeria is recommended.

\section{Limitations}

A potential bias in this study was recall. This might have been present as is usual in self-reported prevalence surveys. Recall bias was reduced by limiting enquiries on outpatient care to one month and admission services to one year. This cut-offs have been used widely in several countries. Another limitation is that income earned were likely to have been overestimated. Analysis was therefore not based on only income. Presence of household assets were used to derive wealth quintiles. Households with higher wealth quintiles were shown to have higher income this implied overestimation of income was minimal or absent.

Ethical issues

Ethical approval to carry out the study was obtained from the Oyo State Ministry of Health Ethical Review Committee.

Competing interests

The authors declare they have no competing interests.

\section{Authors' contributions}

This work was carried out by all authors. All authors contributed to conceptualization of the study. OSI coordinated data collection. Data analysis, discussion, and review of the manuscript were done by all authors. 


\section{Authors' affiliations}

${ }^{1}$ Department of Community Health, Federal Medical Centre, Owo, Ondo State, Nigeria. ${ }^{2}$ Department of Preventive Medicine and Primary Care, College of Medicine, University of Ibadan, Ibadan, Oyo State, Nigeria. ${ }^{3}$ Department of Epidemiology and Medical Statistics, College of Medicine, University of Ibadan, Ibadan, Oyo State, Nigeria.

\section{References}

1. Water HR, Anderson GF, Mays J. Measuring financial protection in health in the United States. Health Policy 2004; 69: 339-49. doi:10.1016/j.healthpol.2004.01.003

2. Ranson MK. Reduction of catastrophic health care expenditures by a community-based health insurance scheme in Gujarat, India: current experiences and challenges. Bull World Health Organ 2002; 80: 613-21.

3. Wagstaff A. Poverty and health sector inequalities. Bull World Health Organ 2002; 80: 97-105.

4. Kawabata K, Xu K, Carrin G. Preventing impoverishment through protection against catastrophic health expenditure. Bull World Health Organ 2002; 80: 612.

5. Wagstaff $A$, Lindelowb $M$, Junc $G$, Lingc $X$, Jonchengc $Q$. Extending health insurance to the rural population: An impact evaluation of China's new operative medical scheme. $J$ Health Econ 2009; 28: 1-19.

6. Obikeze OO, Ige OK, Osungbade KO, Asuzu MC, Olumide AE. An overview of the National Health Insurance Scheme in Nigeria. Dokita 2010; 1: 15-21.

7. NHIS. National Health Insurance Scheme Handbook. Operational Guidelines on National Health Insurance Scheme. Federal Republic of Nigeria: Ministry of Health; 2006. doi: 10.4314/msjm. v3i1.10989

8. Soyibo A. National Health Accounts (NHA) of Nigeria. Federal Republic of Nigeria: Ministry of Health; 2009. doi: 10.4314/ajep. v14i1.44195

9. National Health Insurance Scheme (NHIS). Road map for the implementation of Community-based health insurance scheme in Nigeria. Consultation on Support to NHIS CBSHIS roll-out in Programme States. Abuja: PPRINN-MNCH/NHIS; 2011.

10. Nguyen HT, Rajkotia $Y$, Wang $H$. The financial protection effect of Ghana National Health Insurance Scheme: evidence from a study in two rural districts. Int J Equity Health 2011; 19: 4. doi: 10.1186/1475-9276-10-4

11. Obikeze E, Onwujekwe O, Uzochukwu B, Chukwuogo O, Uchegbu E, Soludo E, et al. Benefit incidence of national health insurance scheme in enugu state, Southeast Nigeria. African Journal Health Econ 2013; forthcoming.

12. Ilesanmi OS, Ige OK. Equity of care: A comparison of National Health Insurance Scheme enrolees and fee-paying patients at a private health facility in Ibadan, Nigeria. J Public Health Epidemiol 2013; 5: 51-5.

13. Akande TM, Ogunrinola EO. Health care financing among inpatients of a tertiary health facility in Ilorin, Nigeria. Niger J Clin Pract 2000; 2: 1-4.

14. Adinma B, Adinma E. Community based healthcare financing: An untapped option to a more effective healthcare funding in Nigeria. Niger Med J 2010; 51: 95-100.

15. Oyo State Health Facility Directory 2007. Ibadan: HMIS Department of Planning Research \& Statistics Oyo State Ministry of Health; 2008.

16. Bender DR. A Refinement of the Concept of Household: Families, Co-residence, and Domestic Functions. Am Anthropol 1967; 69: 493-504. doi: 10.1525/aa.1967.69.5.02a00050

17. van Doorslaer E, O'Donnell O, Rannan-Eliya R, Somanathan A, Adhikari S, Garg C, et al. Effect of payments for health care on poverty estimates in 11 countries in Asia: an analysis of household survey data. Lancet 2006; 368: 1357-64. doi: 10.1016/s01406736(06)69560-3

18. O'Donnell O, van Doorslaer E, Wagstaff A, Lindelow M. Analyzing health equity using household survey data: A guide to techniques and their implementation. Washington, DC: The World Bank; 2008. doi: 10.1596/978-0-8213-6933-3

19. Onoka CA, Onwujekwe OE, Hanson K, Uzochukwu BS. Examining catastrophic health expenditures at variable thresholds using household consumption expenditure diaries. Trop Med Int Health 2011; 16: 1334-1. doi: 10.1111/j.1365-3156.2011.02836.x

20. NPC, ICF Macro. Nigeria Demographic and Health Survey 2008. Abuja: National Population Commission and ICF Macro; 2009.

21. Wagstaff A, Doorslaer E. Catastrophe and impoverishment in paying for health care: with applications to Vietnam 1993-1998. Health Econ 2003; 12: 921-33. doi: 10.1002/hec.776

22. Saksena P, Antunes AF, Xu K, Musango L, Carrin G. Mutual health insurance in Rwanda: evidence on access to care and financial risk protection. Health Policy 2011; 99: 203-9. doi: 10.1016/j.healthpol.2010.09.009

23. Onwujekwe O, Hanson K, Uzochukwu B. Examining Inequities in Incidence of Catastrophic Health Expenditures on Different Healthcare Services and Health Facilities in Nigeria. PLoS One 2012; 7: e40811. doi: 10.1371/journal.pone.0040811

24. Onwujekwe O, Okereke E, Onoka C, Uzochukwu B, Kirigia J, Petu A. Willingness to pay for community-based health insurance in Nigeria: do economic status and place of residence matter? Health Policy Plan 2009; 25: 155-61. doi: 10.1093/heapol/ czp046

25. Ezeoke OP, Onwujekwe OE, Uzochukwu BS. Towards Universal Coverage: Examining Costs of Illness, Payment, and Coping Strategies to Different Population Groups in Southeast Nigeria. Am J Trop Med Hyg 2012; 86: 52-7. doi: 10.4269/ ajtmh.2012.11-0090

26. Ekman B. Catastrophic health payments and health insurance: some counterintuitive evidence from low-income country. Health Policy 2007; 83: 304-13. doi: 10.1016/j.healthpol.2007.02.004 


\section{Key Messages}

\section{Implications for policy makers}

- To address the issue of differentials in catastrophic healthcare expenditure, the government needs to make greater financial allocation to meet the healthcare needs of the poor population.

- The aim of the National Health Insurance Scheme (NHIS) in reducing the burden of healthcare expenditure will not be achieved if the poor are not given special consideration in form of free healthcare.

- Fast-tracking universal coverage of health insurance scheme in Nigeria will ensure financial risk protection and decreased incidence of Catastrophic Health Expenditure (CHE).

- The overall advantage of the NHIS will not be felt if it is limited to only the formal sector. NHIS guidelines stated that apart from those in the formal sector, efforts should be made to protect those that are also in the informal sector of the economy. This will allow the informal sector and the poor to enjoy the financial risk protection it is expected to offers.

- The policy-makers should conduct researches that will help in identifying the problem affecting the NHIS.

\section{Implications for public}

The study showed that in Oyo State, South West Nigeria, National Health Insurance Scheme (NHIS) is limited to those in the employment of the federal government (formal sector). The poor and the non-enrolees are spending a huge proportion of their income on healthcare. This may prevent them from obtaining healthcare services even though they need them. The federal government employee who enjoys the NHIS resides more in the urban communities where there are more healthcare facilities. Those who are poor are actually at a greater disadvantage in terms of payment for healthcare than their richer and urban counterparts. It is highly desirable that the state governments that have not adopted the NHIS should embrace and extend it to their staff. 